\section{Avaliação de políticas públicas de segurança alimentar e combate à fome no período 1995-2002. 2 - Programa de Alimentação do Trabalhador}

\author{
Evaluation of Brazilian public policies to promote \\ food security and fight hunger, 1995-2002. \\ 2 - the Workers' Nutrition Program
}

\author{
1 Departamento de Nutrição, \\ Universidade de Brasília, \\ Brasília, Brasil. \\ 2 Escola de Nutrição, \\ Universidade Federal da \\ Bahia, Salvador, Brasil. \\ 3 Agência Nacional de Saúde \\ Suplementar, Ministério da \\ Saúde, Brasília, Brasil. \\ Correspondência \\ L. M. P. Santos \\ Departamento de Nutrição, \\ Universidade de Brasília. \\ Campus Universitário Darcy \\ Ribeiro, Brasília, DF \\ 70910-900, Brasil. \\ leopac@unb.br
}


e Nutrição (PRONAN), que anunciava o objetivo de enfrentar o problema da desnutrição com ações em duas grandes linhas: a suplementação alimentar a grupos vulneráveis e o estímulo ao pequeno produtor, como forma de aumentar a produção e a comercialização de alimentos básicos.

O Programa de Alimentação do Trabalhador (PAT) foi criado pela Lei $n^{o}$. 6.321/76 que "dispõe sobre a dedução do lucro tributável, para fins de imposto sobre a renda das pessoas jurídicas, do dobro das despesas realizadas em programas de alimentação do trabalhador" 4 , de forma a atender ao item VI das diretrizes básicas do II PRONAN. A justificativa para sua criação foi que, embora não fosse a maior prioridade do ponto de vista biológico, a desnutrição do adulto, quando este é o chefe da família, tem grande repercussão social, pois a diminuição ou supressão de seus rendimentos afeta decisivamente a capacidade de sobrevivência do grupo familiar 5 .

O documento do Ministério do Trabalho datado de 1979 e intitulado Incentivos Fiscais para Alimentação do Trabalhador, define como objetivos principais do PAT: "proporcionar disponibilidade maior e mais eficiente de energia para o trabalho do homem e, conseqüentemente, concorrer para melhoria do estado nutricional do trabalhador; dividir, transitoriamente, entre o governo, a empresa e o trabalhador, o custo da energia humana necessária para o trabalho" 6 (p. 6).

Observa-se, portanto, que a intervenção alimentar na direção dos trabalhadores conta no Brasil com uma história de mais de 30 anos. Trata-se de um programa importante tanto pelas características da população alvo, como por sua dimensão, registrando quase 9 milhões de beneficiários em 2002. No entanto, avaliações empíricas da cobertura, focalização e do alcance dos objetivos do programa são raras.

Este estudo realizou uma avaliação do PAT no período 1995-2002 e um estudo de caso no Estado da Bahia, aplicando o enfoque muldimensional baseado na tríade estrutura-processo-resultado 7 , visando contribuir com informações para o aperfeiçoamento do programa.

\section{Metodologia}

A avaliação foi baseada no enfoque multidimensional, anteriormente descrito em detalhe 7. Para a identificação das variáveis e construção dos instrumentos de coleta de dados foi desenhada uma matriz específica para o PAT.

Para a análise da dimensão da estrutura foram considerados neste estudo os instrumentos normativos-legais do PAT, desde a sua criação até o ano de 2002, obtidos por extensa pesquisa documental. A dimensão do processo contemplou a análise de estudos sobre a operacionalização do programa, observando-se os aspectos positivos e negativos decorrentes de sua implementação (externalidades). Já para a avaliação da dimensão resultado, os dados sobre cobertura e focalização do benefício foram analisados a partir de: (a) dados oficiais sobre o programa no período em estudo (1995-2002); (b) dados empíricos do estudo de caso na Bahia, cuja metodologia foi descrita anteriormente ?.

A amostra do estudo de caso foi selecionada de modo intencional, para representar a população de mais baixa renda do Estado da Bahia. Dentre os 96 municípios beneficiados pelo Programa Comunidade Solidária em 1996, 44 foram selecionados para a pesquisa. Em cada município 40 famílias (20 urbanas e 20 rurais), residentes nos bairros e/ou povoados de mais baixa renda, foram selecionadas ao acaso e responderam ao questionário, resultando numa amostra de 3.372 indivíduos maiores de vinte anos distribuídos em 1.655 famílias 7. Na capital (Salvador) foram incluídas localidades de baixa renda atendidas pelo Programa Saúde da Família, sendo estudados 1.748 indivíduos distribuídos em 734 famílias 7.

\section{Resultados e discussão}

O modelo metodológico adotado para o desenvolvimento deste estudo implicou a identificação de categorias de análise orientadoras da investigação em cada uma das dimensões consideradas, de acordo com as características do programa em avaliação. No caso do PAT, as categorias privilegiadas foram: modelo de gestão, definição da população alvo, modalidade de distribuição do benefício, recomendações nutricionais, cobertura e focalização.

\section{Dimensão de estrutura}

\section{- Modelo de gestão}

A análise documental revelou que inicialmente a operacionalização do programa pressupunha um modelo de gestão colegiada, contemplando a participação de diferentes segmentos, tanto que em 1976 foi criada uma comissão especial integrada por representantes do Ministério do Trabalho, do Ministério da Fazenda e do INAN, sendo constituída por dois representantes de cada órgão. Essa comissão tinha como papel principal o registro das empresas no PAT e o exame e aprovação das propostas de implementação por elas apresentadas. 
Em 1985, porém, a competência da comissão passa a ser: "examinar a capacidade das empresas requerentes do registro, de acordo com o estabelecido em portaria, proferindo parecer que encaminhará à deliberação do Secretário de Promoção Social do Ministério do Trabalho" 8 (p. 118). Dessa forma, ficou delegada competência ao Ministério do Trabalho para "decidir sobre o registro das empresas participantes do PAT e expedir as certidões comprobatórias da aprovação dos programas" 8 (p. 118).

Contudo, quatro anos depois, as competências da comissão são retomadas, inclusive com avanços em relação à sua composição, com base na Portaria no. 3.282/89, que instituiu, novamente, a comissão especial ${ }^{9}$. Nessa nova conformação incorpora dois representantes dos trabalhadores e dois dos empregadores, um do INAN, outro do Ministério da Fazenda e dois do Ministério do Trabalho, sob a presidência de um dos representantes do Ministério do Trabalho.

A década de 90 traz uma simplificação no processo de inclusão das empresas no programa (desburocratização), ficando as propostas automaticamente aprovadas mediante apresentação e registro do formulário oficial na Empresa Brasileira de Correios e Telégrafos (ECT), sem passar por uma avaliação prévia. O modelo de gestão passa a ser centralizado, não inclusivo, desde que não pressupõe a formação de colegiado/comissão e as decisões tomadas em nível central são repassadas para cumprimento no nível local.

Diante da necessidade de reestruturação do programa, em 1997, institui-se, no âmbito do Ministério do Trabalho, uma Comissão Tripartite com a finalidade de acompanhar e avaliar a execução do PAT 10. A nova composição é diferenciada daquela prevista em 1989: um representante do Ministério do Trabalho, que a presidirá; um do Ministério da Fazenda; um do Ministério da Saúde; três dos trabalhadores e três dos empregadores. A Portaria estabelece que os representantes do governo federal serão indicados pelos titulares dos respectivos órgãos, sendo os representantes dos trabalhadores e empregadores indicados pelas entidades representativas de âmbito nacional.

A intensa descentralização observada na gestão pública brasileira a partir da década de 90 , não se faz presente ainda nos processos decisórios relativos ao PAT. Ainda que o programa seja executado fundamentalmente no interior das empresas, a autonomia neste espaço é mínima. Dessa forma, levando-se em conta o processo de gestão do programa, o espaço para as decisões locais, considerando particularmente a empresa e os trabalhadores, beneficiários da ação, limita-se às questões mais operacionais da produção das refeições e/ou da forma de distribuição do benefício aos trabalhadores. No entanto, a participação dos trabalhadores que vem se dando através das entidades representativas da classe nas reuniões da comissão instituída em 1997, pode ser entendida como um importante avanço da luta dos mesmos pelo direito de participar no processo decisório da implementação do programa.

\section{- Definição da população alvo}

A Lei $n^{\circ}$. 6.321/76, no seu artigo 2o, afirmava que o PAT deveria conferir prioridade ao atendimento dos trabalhadores de baixa renda contratados pela pessoa jurídica beneficiária 4 . A partir do Decreto $n^{o}$. 05/91, estabeleceu-se o ponto de corte de cinco salários mínimos como a clientela prioritária do programa 11. A Portaria do Ministério do Trabalho $n^{\circ}$. 87/97, reforça tal condição 12: “as pessoas jurídicas beneficiárias poderão incluir no Programa trabalhadores de renda mais elevada, desde que esteja garantido o atendimento da totalidade dos trabalhadores que percebam até 5 (cinco) salários-mínimos, independentemente da duração da jornada de trabalho".

Relevante observar, nessa mesma portaria, a orientação de que "o benefício concedido aos trabalhadores que percebam até 5 (cinco) saláriosmínimos não poderá, sob qualquer pretexto, ter valor inferior àquele concedido aos de renda mais elevada" 12, o que parece indicar a preocupação de que a extensão do benefício a trabalhadores de maior renda acarretasse maiores desigualdades dentro do sistema. Em 1991 foi introduzida a obrigatoriedade de atendimento a todos os trabalhadores com salários inferiores a cinco salários mínimos, provavelmente devido à constatação da falta da eqüidade no acesso ao benefício.

Em 1998 é publicada a Medida Provisória no. 1.709 que estende o benefício do PAT para os trabalhadores dispensados 13. Inclui-se, portanto, a possibilidade de extensão da cobertura do programa como um benefício social complementar ao salário desemprego, porém de caráter opcional.

O PAT é um programa vinculado ao trabalho formal, sem cobertura no mercado informal e nas zonas rurais. No debate sobre quem deveria ser o beneficiário do PAT, uma das críticas mais acirradas ao programa refere-se ao fato de não atender trabalhadores autônomos e do setor informal da economia, um segmento de máxima importância pelo número de trabalhadores envolvidos e pelo que significa na sociedade brasileira. Essas condições fazem com que o PAT seja identificado como uma ação pública que discrimina de forma negativa regiões de economias menos desenvolvidas e industrializadas, como o nordeste e norte do Brasil. 


\section{Dimensão de processo}

\section{- Modalidades de distribuição do benefício}

Observa-se que estas modalidades vieram sendo modificadas progressivamente na direção de um redesenho total da política, contemplando maior complexidade quanto às modalidades da oferta dos benefícios e alterações quanto à oferta calórica preconizada. Desde 1976, quando da criação do PAT, as pessoas jurídicas beneficiárias podiam manter serviço próprio de refeições, distribuir alimentos ou firmar convênio com entidades fornecedoras de alimentação coletiva, sociedades civis, sociedades cooperativas e órgãos públicos, visando à execução do programa.

Em 1985, foi instituída portaria que disciplinou o registro das empresas especializadas em refeições-convênio e estabeleceu normas para o funcionamento deste sistema ${ }^{8}$. Inicialmente, o sistema convênio constituía-se apenas de cupons para aquisição de refeições prontas em restaurantes (ticket refeição). Posteriormente o uso dos cupons foi estendido para a aquisição de gêneros alimentícios em estabelecimentos comerciais credenciados (ticket alimentação). Esta última modalidade pode ser entendida como uma oportunidade de estender o benefício à família e, em geral, resulta como salário indireto conquistado, por vezes, quando da mobilização por aumento salarial.

Atualmente, as modalidades de serviços integrantes do PAT são: (a) Serviço próprio ou autogestão, no qual a empresa beneficiária assume toda responsabilidade pela elaboração e distribuição das refeições; (b) Serviços de terceiros (terceirização) em que o fornecimento das refeições é formalizado por meio de convênios firmados entre a empresa beneficiária e empresas que prestem serviços de alimentação coletiva, desde que estas entidades estejam registradas no PAT e se obriguem a cumprir o disposto na legislação do programa; (c) Prestadora de serviço de alimentação coletiva, ou seja, administradora de tickets ou cupons 14 .

Quanto à dimensão do processo, o que se observa é o crescimento da terceirização e do sistema de alimentação ou refeição convênio (tickets) em detrimento da auto-gestão. O crescimento do sistema convênio no âmbito do PAT pode ser um limitante para a garantia de uma alimentação saudável ao trabalhador. Como já citado, o convênio surgiu para atender aos trabalhadores das empresas de pequeno e médio porte, como alternativa para aquelas sem condições de manter serviços de alimentação ou refeitórios. Implantado na década de 80 , esse tipo de sistema cresceu enquanto modalidade de serviço ao longo do tempo. Dados de 1990 apresentaram um porcentual de $51,8 \%$ de atendimento dos trabalhadores beneficiados pelo PAT no país pela modalidade convênio ${ }^{15}$. Registrou-se no período de 1980 a 1995 um aumento da ordem de $40,1 \%$ na adoção dessa modalidade 16 .

Um dos subprojetos desta pesquisa analisou os dados do Estado da Bahia para o ano de 1996, demonstrando que $63,7 \%$ dos atendimentos aos trabalhadores beneficiados pelo PAT foram realizados por meio do sistema convênio 17. Um aspecto considerado positivo nessa modalidade é uma maior autonomia por parte do trabalhador em relação à escolha do local e tipo de refeição, porém existe a possibilidade da utilização para outros fins que não os alimentícios, o que se caracterizaria como um desvirtuamento dos objetivos do programa.

\section{- Recomendações nutricionais do Programa de Alimentação do Trabalhador}

No que tange ao aporte nutricional previsto na estrutura do programa, observa-se que de 1976 até 1999 as exigências nutricionais mínimas das refeições fornecidas mantiveram-se as mesmas: $1.400 \mathrm{Kcal}$ para as grandes refeições - almoço, jantar e ceia, e 300 calorias para as pequenas refeições - desjejum e merenda. Desse valor calórico, $6 \%$ ou mais deveriam ser fornecidos pela proteína líquida da dieta (NDpCal). Porém a Portaria Interministerial no. 5/99 18 admite uma redução para $1.200 \mathrm{Kcal}$ no caso de atividade leve, ou acréscimo para $1.600 \mathrm{Kcal}$ no caso de atividade intensa, para as grandes refeições, mediante justificativa técnica, observando-se que, para qualquer tipo de atividade, o porcentual protéico-calórico (NDpCal) deverá ser, no mínimo, de 6\%.

Este estudo não avaliou empiricamente o atendimento das recomendações nutricionais. Existem, no entanto, resultados de estudos que contribuem para essa análise. Na década de 80 a análise dos cardápios oferecidos por empresas cadastradas no programa no Estado de Pernambuco ${ }^{19}$, estimou que apenas $15,8 \%$ destes atendiam às exigências energético-protéicas estabelecidas pelo programa. Já nos anos 90 ao analisar o potencial alimentar dos cardápios elaborados pelo PAT na região metropolitana de São Paulo², foi verificado que os cardápios, não obstante a significativa contribuição em energia e proteínas, se mostravam inadequados em relação ao fornecimento de micronutrientes. Através do índice de qualidade nutricional, o estudo evidenciou a inadequação moderada de tiamina, riboflavina, niacina, cálcio e vitamina A dos cardápios quando oferecidos aos trabalhadores do sexo masculino. Entre as trabalhadoras, o por- 
centual de inadequação aumentava e se estendia a outros nutrientes analisados, tais como o ferro e a vitamina $\mathrm{C}^{2}$.

Já em 2000, estudando uma indústria incentivada pelo PAT no Estado da Bahia, foi observado que considerando apenas a alimentação no ambiente de trabalho, o trabalhador estava consumindo, em média, 96,1\% das recomendações energéticas diárias $(2.218 \mathrm{Kcal}) 20$. Outro estudo epidemiológico de coorte dinâmica retrospectiva entre trabalhadores baianos avaliou o impacto do PAT sobre o estado nutricional, encontrando associação positiva, estatisticamente significativa, entre apresentar aumento de peso e ser trabalhador de empresa credenciada no PAT 21.

$\mathrm{O}$ estabelecimento das recomendações nutricionais mínimas no PAT é questionável, pois para uma população alvo heterogênea e diversificada, as recomendações apresentadas podem não ser as mais adequadas. Outro fato de fundamental importância a ser assinalado é o momento histórico em que o programa foi concebido, numa época em que a desnutrição representava um grave problema de saúde pública e o déficit calórico a que poderiam estar submetidos os trabalhadores brasileiros poderiam repercutir na produtividade 22,23 . Para a época em que o programa foi desenhado, os critérios utilizados para determinação desse valor calórico eram válidos.

Desde os anos 90, no entanto, estudos vêm revelando que o Brasil enfrenta a transição nutricional, registrando prevalência crescente de obesidade entre homens e mulheres adultos, convivendo com duas realidades. Estudo do IBGE datado de 2003 encontrou no Brasil 4\% de adultos desnutridos, contra $40,6 \%$ com sobrepeso e $11,1 \%$ com obesidade 24 .

Dessa forma, um programa que se inscreve no âmbito da busca da saúde para o trabalhador pode, pela falta de acompanhamento e avaliação, somar fatores de risco importantes para quadros mórbidos de importância epidemiológica atualmente, como a obesidade e as doenças cardiovasculares 20,21. Se confirmado por outros estudos, esse será, sem dúvida, um aspecto negativo decorrente da implementação do programa (externalidade). Como não se dispõe de estudos epidemiológicos longitudinais para evidenciar a relação causa-efeito do PAT no estado de saúde e nutrição dos seus beneficiários, fica impossível imputar ao Programa mudanças no perfil nutricional da população trabalhadora adulta brasileira.

A preocupação sobre como a alimentação no trabalho pode contribuir para solucionar a desnutrição, obesidade e doenças crônicas, não ocorre só no Brasil, mas inseriu-se definitivamente na agenda internacional, tanto assim que uma publicação recente da Organização Internacional do Trabalho 25 trata especificamente deste assunto.

\section{Dimensão de resultados}

O investimento governamental no PAT, na forma de renúncia fiscal, passou a ser mais amplamente divulgado pela Secretaria da Receita Federal a partir de 1998. Segundo essa fonte, o custo anual da renúncia fiscal no período estudado flutuou entre 95,9 (1998), 90,8 (1999), 155,5 (2000), 103,3 (2001) e 135,9 milhões de Reais (2002) o que correspondeu a cerca de $\mathrm{R} \$ 1,42$ por trabalhador/ mês, ou seja, R\$17 por trabalhador/ano 26,27.

O número de trabalhadores beneficiados pelo PAT cresceu gradativamente desde a sua criação e alcançou 8,7 milhões de trabalhadores no ano 2002 (Figura 1). Analisando o período em estudo (1995-2002), houve um incremento de $51 \%$ no número de beneficiários. Segundo a mesma fonte (Ministério do Trabalho e Emprego), no caso do Estado da Bahia o número de beneficiários era de 161 mil em 1995 e passou a 219 mil em 2002, apresentando um incremento de $36 \%$, bem mais modesto.

Analisando a distribuição regional do programa, a situação do PAT expressa de forma contundente a desigual distribuição do desenvolvimento econômico no país. Em números absolutos a distribuição dos trabalhadores beneficiados por Unidade da Federação é extremamente desigual, com marcante concentração nos estados da região Sudeste, onde se encontra a maioria dos empregos formais. Para ilustrar essa disparidade selecionou-se, como exemplo, 1999; analisando-se a proporção de beneficiários do PAT por região, observou-se que o Sudeste concentrava $67,1 \%$; seguido pelo Sul 16,7\%; Nordeste 8,9\%; Centrooeste $5,0 \%$ e Norte com 2,3\% (Figura 2).

Para avaliar a cobertura do PAT levou-se em consideração a proporção do número de beneficiários/população alvo do programa (trabalhadores com carteira assinada). Em 1999, segundo a Pesquisa Nacional por Amostra de Domicílios 28, havia 43,1 milhões de trabalhadores no Brasil, porém apenas 21,5 milhões com carteira assinada. O número de beneficiários do PAT era 6,6 milhões, resultando numa cobertura nacional média de $30,7 \%$. No Sudeste a cobertura foi de $36,5 \%$ enquanto a registrada no Nordeste foi de $18,1 \%$, a mais baixa entre as regiões (Figura 3). Conclui-se que, em 1999, a cobertura do programa foi muito baixa e que a focalização do programa foi perversa ao privilegiar cobertura duas vezes maior entre os trabalhadores da região Sudeste, a mais desenvolvida do país. Segundo outros autores, a 


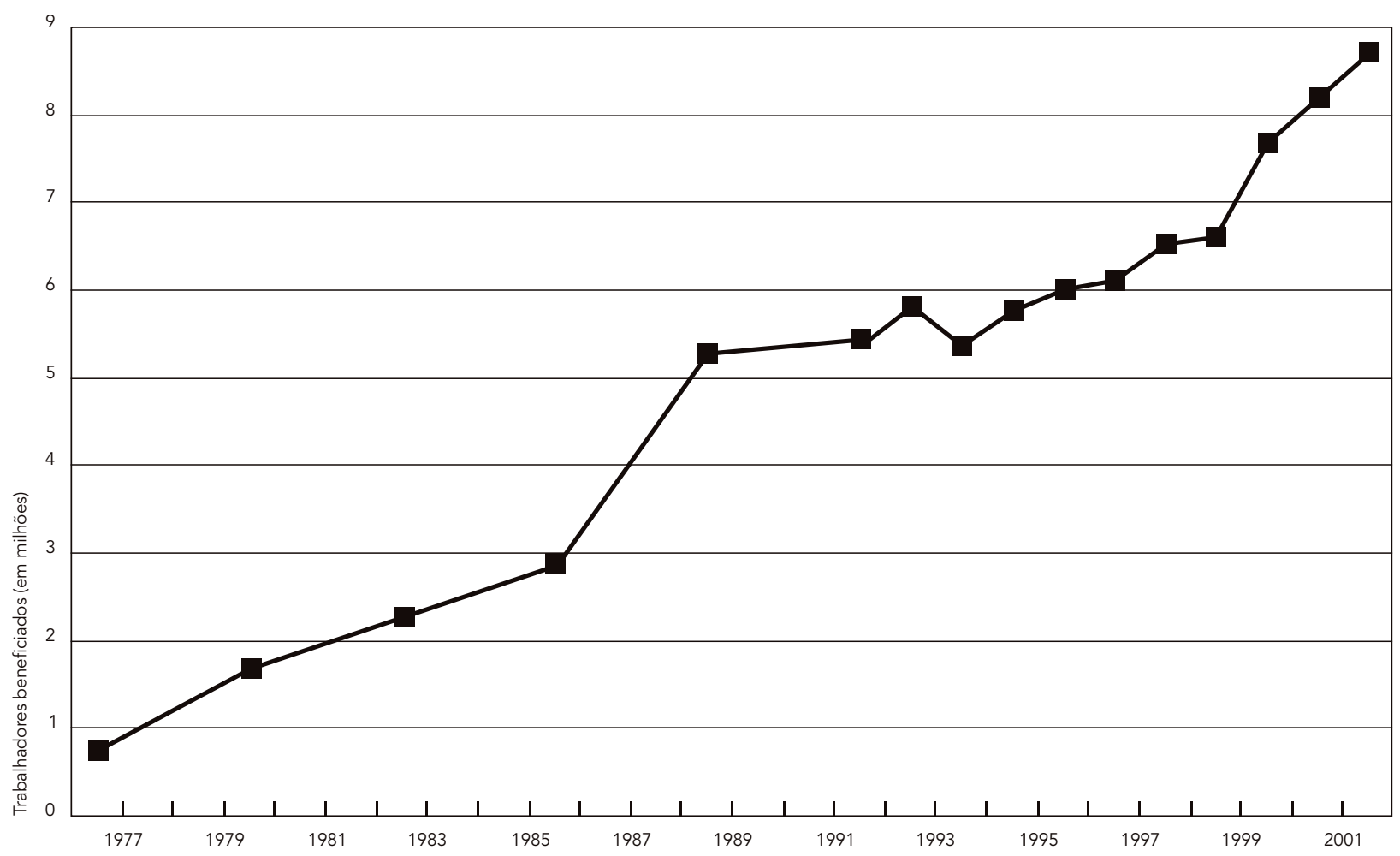

Fonte: Mazzon 16 [para 1977-1989]; Ministério do Trabalho e Emprego: http://www.mte.gov.br/Empregador/PAT/Relatorios_graficos/Conteudo/beneficiados. asp (acessado em 16/Jan/2007) [para 1992-2002].

cobertura nacional em 1995 era de cerca de $40 \%$ dos trabalhadores formais 16 .

Importou ao estudo considerar a cobertura do programa, tanto em termos nacionais, como no estudo empírico realizado na capital e em outros 44 municípios baianos. No estudo de caso foram investigados 3.372 indivíduos no interior da Bahia, com idade igual ou superior a 20 anos, dos quais $1.867(55,4 \%)$ declararam ter trabalhado no mês de referência da pesquisa, com freqüência significativamente maior para o sexo masculino $(64,8 \% \mathrm{p}=0,000)$ e também para a área rural dos municípios $(58,4 \% \mathrm{p}=0,000)$ (Figura 4). Em relação ao nível de pobreza, a situação entre os que não trabalhavam era significativamente mais desfavorável $(\mathrm{p}=0,000)$; em ambos os grupos havia clara predominância de indivíduos abaixo da linha de indigência, como esperado, tendo em vista a amostra intencional selecionada. Já o tipo de ocupação mais freqüente foi o trabalho autônomo (49,5\%), seguido por empregados (46,1\%) (Figura 4). Ressalta-se que neste estudo, cerca de $25 \%$ dos empregados no interior estavam inseridos no mercado de trabalho no ramo da agricultura, em sua maioria com vínculo temporário. Porcentual superior a $75 \%$ dos trabalhadores autônomos também trabalhavam no ramo da agricultura, na produção de alimentos para subsistência.

$\mathrm{Na}$ capital foram estudados 1.748 indivíduos com vinte anos e mais e destes, $1.121(64,1 \%)$ declararam ter trabalhado no mês de referência, com maior porcentual também para o sexo masculino $(57,5 \% \mathrm{p}=0,000)$. Como esperado, a situação de pobreza e indigência era mais freqüente entre o grupo que não trabalhava $(p=0,000)$, mas em ambos os casos o maior percentual de indivíduos encontrava-se na situação de não-pobres. Já o tipo de ocupação mais freqüente foi o de empregados $(66,9 \%)$, seguido por autônomos $(32,5 \%)$ (Figura 4$)$. 


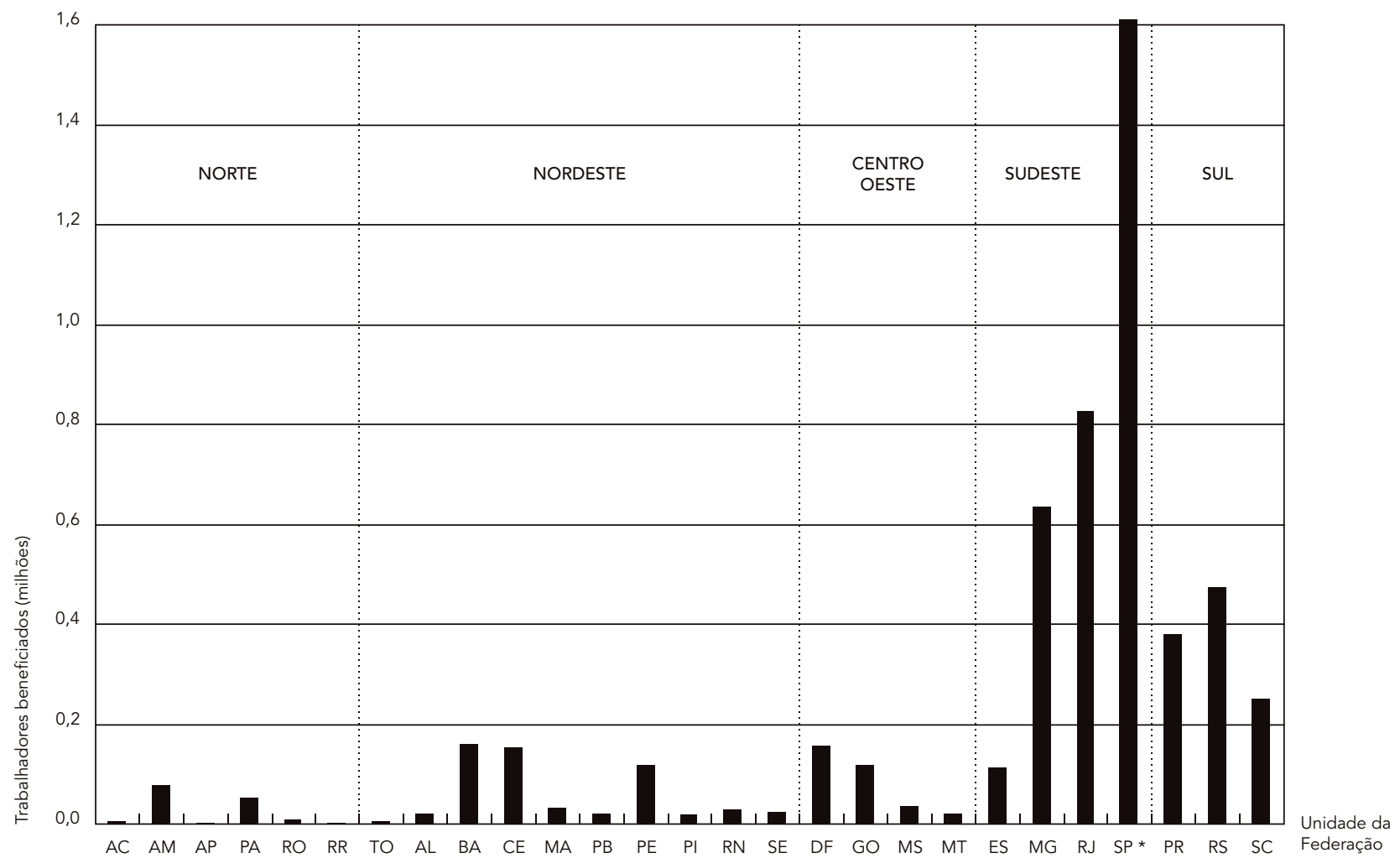

* São Paulo $=2,86$ milhões.

Fonte: Ministério do Trabalho e Emprego. http://www.mte.gov.br/Empregador/PAT/Relatorios_graficos/Conteudo/beneficiados.asp; (acessado em 16/ Jan/2007)

Na comparação entre interior e capital chamou atenção a elevada proporção de homens adultos que não trabalham no interior (quase $30 \%$ ), enquanto na capital este porcentual foi de 17,4\%. Em Salvador, o maior percentual de indivíduos se encontrava na situação de não-pobre (54,5\%), em comparação com o interior $(21,6 \%)$, ainda que o critério de seleção de amostra tenha focalizado as comunidades pobres da capital. A proporção relativa de mulheres incorporadas ao mercado de trabalho foi maior na capital $(42,5 \%)$ do que no interior $(35,2 \%)$ ( $p=000)$, fato que pode suscitar as seguintes hipóteses: (a) na capital as mulheres estão mais emancipadas e economicamente ativas; (b) no interior a participação da mulher na agricultura não é reconhecida como trabalho (Figura 4). Ressalta-se que durante a coleta dos dados, realizada em horários diurnos, nem sempre foi possível entrevistar diretamente o trabalhador, o que justifica a dificuldade de se obter todos os dados referentes ao vínculo, tipo de benefício, etc.

Do total de 1.867 indivíduos que trabalharam no interior no mês de referência da pesquisa, 861 eram empregados $(46,1 \%)$ (Figura 4), contudo só foi possível coletar informações sobre tipo de vínculo empregatício e beneficio alimentar para 804 empregados (Figura 5). Desse total, apenas $96(11,9 \%)$ constituíam o público-alvo do PAT, pois referiram possuir vínculo formal de trabalho; o altíssimo porcentual de informalidade nas relações de trabalho chamou atenção no interior. Dentre esses foi possível obter informações sobre o recebimento de benefícios para 86 indivíduos e $23(26,8 \%)$ referiram acesso a algum tipo de benefício, sendo ticket refeição o mais comum. Foi também informado benefícios alimentares para 85 trabalhadores que alegaram não pos- 
Figura 3

Número de trabalhadores com carteira assinada e cobertura do Programa de Alimentação do Trabalhador segundo a região geográfica. Brasil, 1999.

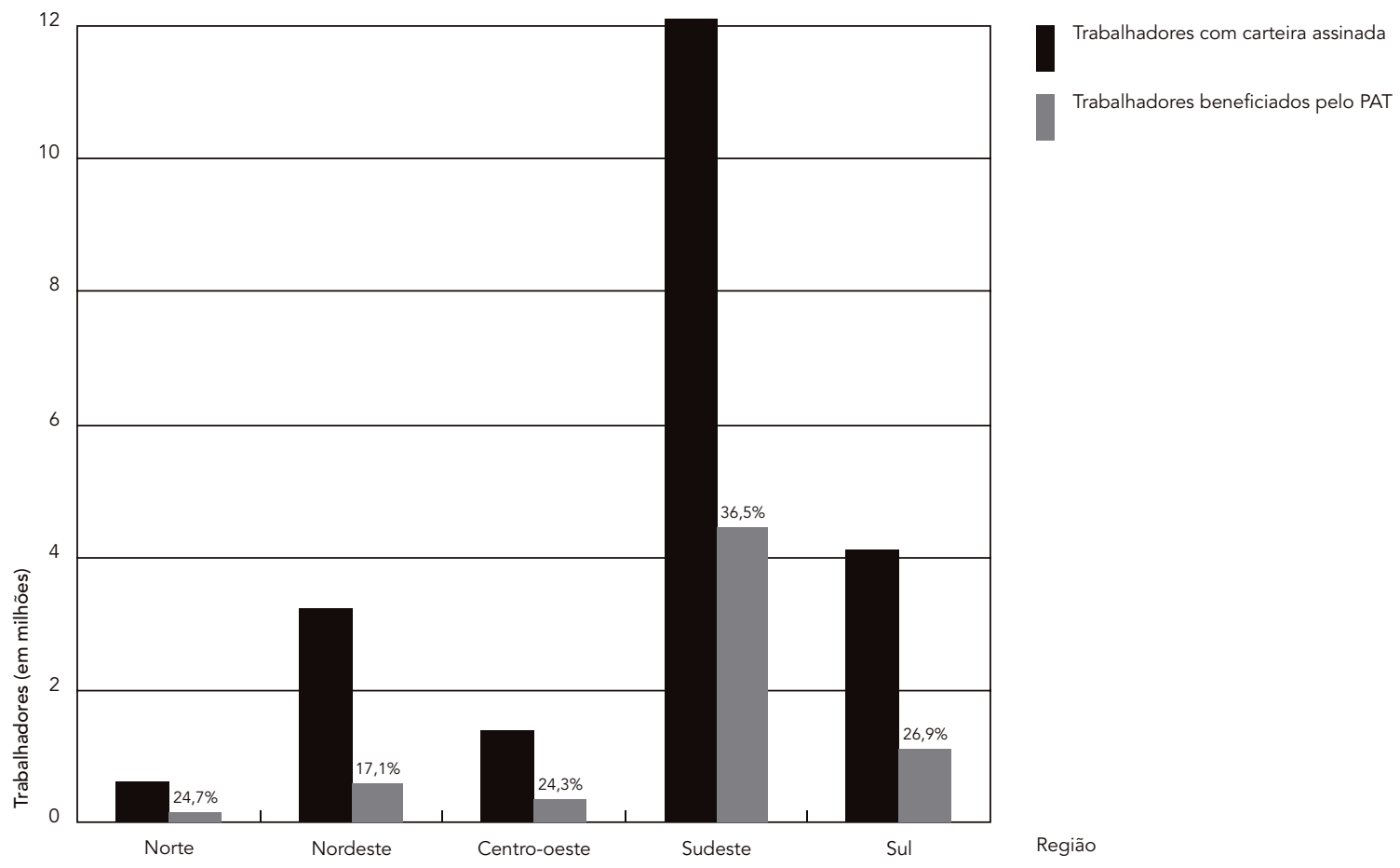

Fonte: Instituto Brasileiro de Geografia e Estatística 28; Ministério do Trabalho e Emprego: http://www.mte.gov.br/Empregador/PAT/Relatorios_graficos/ Conteudo/beneficiados.asp (acessado em 16/Jan/2007).

suir vínculo formal com o empregador (13,9\%) e para 6 entre os que não responderam sobre a existência de vínculo empregatício (15,4\%), sendo a alimentação na empresa o mais comum em ambos os casos (Figura 5). A cobertura de benefícios alimentares entre todos os trabalhadores do interior foi de 26,1\% (293 de 1.867) e pode ser considerada irrisória; cumpre lembrar que $52 \%$ destes são classificados como indigentes.

Para os 1.121 indivíduos da capital que informaram ter trabalhado no mês de referência da pesquisa, foram encontrados $750(66,9 \%)$ na categoria de empregados (Figura 4), contudo só foi possível coletar informações sobre tipo de vínculo empregatício e beneficio alimentar para 736 empregados (Figura 6). Desses, 514 (68,5\%) indicaram possuir vínculo formal com o empregador. Do total de indivíduos com vínculo formal com o empregador foram obtidas informações sobre o recebimento de auxílio alimentação para 496, sendo encontrado um porcentual de 50,2\% (249 indivíduos) que receberam algum tipo de auxílio.
Dentre os 222 trabalhadores da capital entrevistados, sem vínculo, foi possível obter respostas sobre acesso a algum auxílio em alimentação para 200. Entre esses, $17,5 \%$ referiram recebimento de benefícios alimentares (Figura 6). A cobertura encontrada na capital foi de 22,2\% (249 de 1.121 trabalhadores).

A focalização do benefício alimentar foi analisada entre a população estudada na Bahia. Todos os trabalhadores beneficiados no interior (que tiveram acesso ao benefício alimentar com ou sem vínculo formal) recebiam menos que cinco salários mínimos (100\%); na capital, 230 dos 249 trabalhadores beneficiados $(92,4 \%)$ recebiam menos que cinco salários mínimos. A focalização, portanto, parece adequada e não diferiu estatisticamente entre o interior e a capital (teste de Probabilidade Exata de Fisher $\mathrm{p}=0,175$ ). Porém, essa análise deve levar em conta o fato de que a amostragem deste estudo foi intencional e direcionada para a população de baixa renda. No entanto, uma questão sempre controversa em 

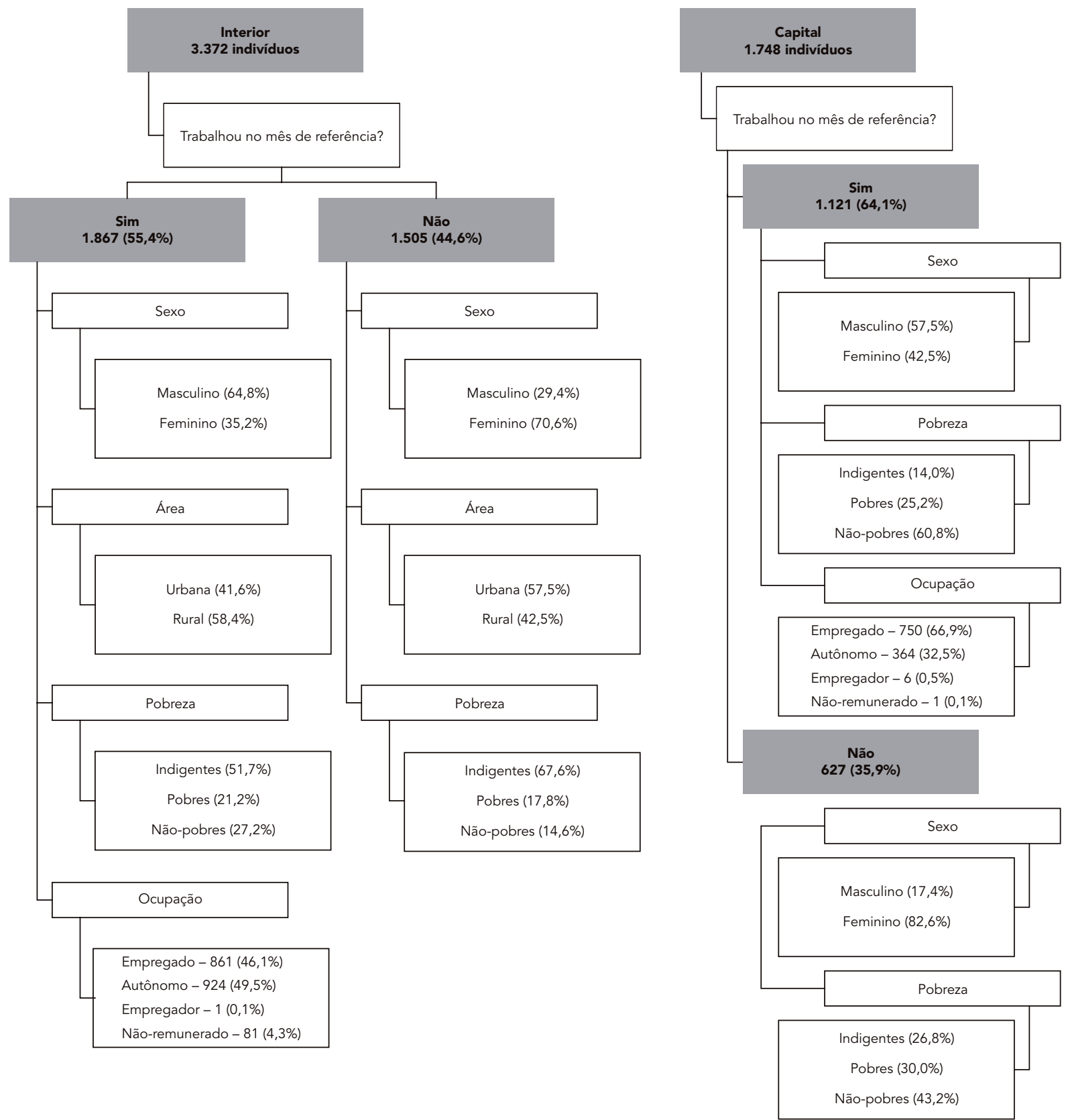

relação ao programa é a concessão do benefício independentemente da faixa salarial.

Em termos nacionais, em 1995, do total de beneficiários, $48,7 \%$ percebiam mais de cinco salários mínimos e este porcentual vem decrescendo lentamente, para 39,7\% (1996), 38,3\% (1997) até alcançar 37,9\% em 1999 e, no início da década de 80, 29,0\% acima de cinco salários mínimos 26. Outros estudos sobre a implementação do PAT demonstraram que apesar de objetivar a melhoria das condições nutricionais da classe trabalhadora, especialmente a de baixa renda, 
Figura 5

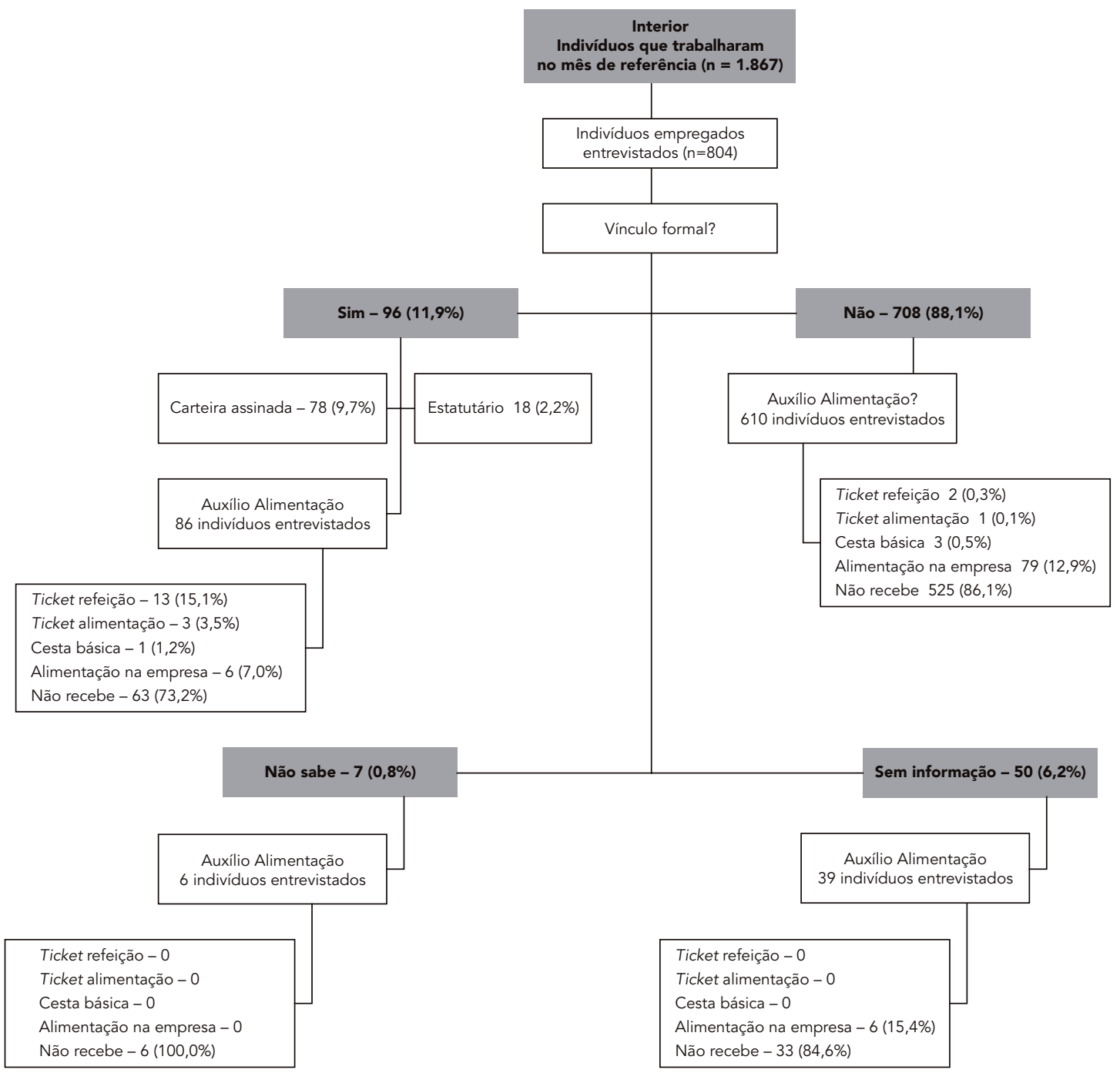

este acaba concentrando seu atendimento nas regiões e estratos de maior renda 2,25,29.

Esses números revelam que a focalização benefício está longe de ser adequada. A publicação da OIT anteriormente mencionada 25 , ao analisar o PAT, pondera que o programa é extenso, mas não consegue atingir a parcela de trabalhadores mais pobres, que trabalham no setor informal ou em pequenas empresas excluídas do programa, por uma série de razões burocráticas.

Um dos resultados obtidos no estudo empírico refere-se à visibilidade do PAT entre os trabalhadores e suas famílias. Isto é, importou ao estudo reconhecer o grau de conhecimento sobre o PAT entre potenciais beneficiários. Entre indivíduos entrevistados no interior da Bahia, apenas $15 \%$ declararam ter algum tipo de conhecimento sobre o programa, sendo o rádio o principal meio de comunicação para obtenção de tal informação (39\%), seguido da televisão (34\%). Já na capital, 20\% dos indivíduos maiores de 20 anos relataram algum conhecimento sobre o PAT, sendo a televisão o principal meio de comunicação (54\%). A proporção de conhecimento sobre o PAT nos dois grupos ( $15 \%$ e $20 \%$ ) pode ser considerada extremamente baixa, tendo em 
Figura 6

Cobertura na população estudada por tipo de benefício alimentar. Salvador, Bahia, 2000

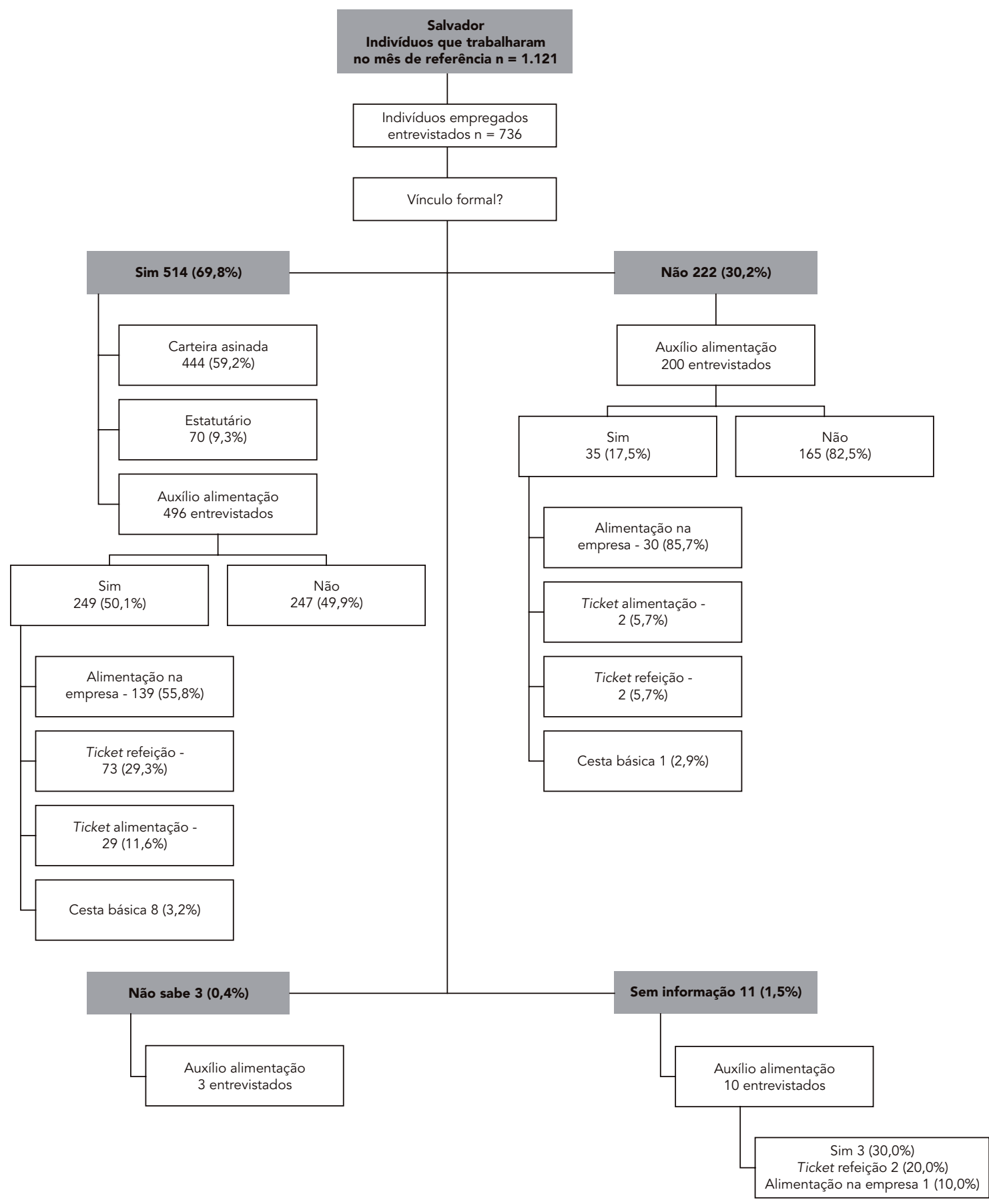


vista tratar-se de um programa com tantos anos de existência, o que parece indicar que ele não tem sido suficientemente divulgado entre os potenciais interessados; o acesso a este tipo de informação é um requisito básico para a conquista de direitos.

Os achados deste estudo põem em evidência importante diferencial regional, e entre a capital e o interior quanto à situação de trabalho, tipo de vínculo e acesso a benefícios alimentares, com ou sem referência ao programa. Esses resultados ressaltam as observações de vários autores sobre a não focalização do PAT nos grupos economicamente mais vulneráveis.

Considerando a dimensão do resultado no que se refere à modalidade de distribuição do benefício, o estudo empírico revelou que mais de $50 \%$ dos trabalhadores de Salvador que participaram do estudo recebiam alimentação na empresa, na modalidade terceirizada. Outros $29 \%$ eram beneficiários do ticket refeição; as modalidades ticket alimentação e cesta básica juntas alcançaram 15\% dos entrevistados (Figura 6). Esse resultado é compatível com o que vem sendo observado no país e pode ser analisado como expressão de uma tendência em torno do tratamento da função alimentação nas empresas como algo à parte de sua política de saúde e segurança do trabalhador.

\section{Conclusões}

Apesar do PAT estar comemorando 30 anos de implementação, poucos são os estudos que avaliam de forma mais abrangente o alcance de seus objetivos. O seu propósito, como originalmente formulado: "dividir entre o governo, a empresa e o trabalhador, o custo da energia humana necessária para o trabalho" 6 (p. 6), se apresentaria totalmente inapropriado numa análise contemporânea, à luz do direito humano à alimentação. Porém, ao longo do tempo, essa formulação foi se modificando 12 e atualmente o PAT objetiva " $a$ melhoria da situação nutricional dos trabalhadores, visando promover sua saúde", compatível com um programa nacional de promoção da segurança alimentar e nutricional.

Neste estudo fez-se uma avaliação do programa sob a ótica de estrutura-processo-resultado. Em termos de estrutura, a análise documental realizada permitiu verificar a evolução normativa do PAT ao longo de sua existência. A tendência de descentralização observada na gestão pública brasileira a partir da década de 90, não alcançou este programa. Centralizado, podendo ser exemplo de uma ação governamental essencialmente normativa, cuja lógica central foi modulada há 30 anos em um cenário social e econômico bastante diverso, pode-se dizer que o programa pouco mudou na medida em que não introduziu estratégias inovadoras que pudessem torná-lo mais adequado ao mundo do trabalho contemporâneo.

A obrigatoriedade da empresa cadastrada no PAT atender a todos os trabalhadores com salário inferior a cinco salários mínimos foi um grande avanço político do programa. No entanto, parte desses trabalhadores está em empresas que não aderiram ao programa ou no mercado informal. Outra parcela importante de trabalhadores, principalmente em se tratando de alcançar os mais pobres, é representada pelos trabalhadores rurais, que ficam sem os benefícios gerados pelo programa, como constatado no presente estudo.

Além disso, uma vez que a adesão ao programa é espontânea, boa parte das empresas, principalmente as pequenas e médias, sabidamente as que mais empregam no país, não se interessa pelo credenciamento. Isso parece indicar que a estrutura de incentivos do programa precisa ser revista.

Os achados do estudo de caso realizado em Salvador e em 44 municípios baianos evidenciam importantes diferenças entre capital e interior quanto à situação de trabalho, tipo de vínculo e acesso a benefícios alimentares. Em termos gerais a cobertura no grupo estudado ficou muito aquém do desejável, 2,1\% no interior e 22,2\% na capital. Decerto na medida em que a amostra intencional selecionou os setores mais pobres da população, defrontou-se com o desemprego, o subemprego e com a informalidade, o que faz destes trabalhadores uma clientela excluída de um programa que está atrelado ao emprego formal, desde que a empresa opte pela adesão.

Quanto ao atendimento das necessidades nutricionais dos trabalhadores, o programa passou, em alguns casos, de uma insuficiente adequação calórica encontrada nos anos 80, para uma superalimentação no trabalho, representando mais de 96\% das recomendações energéticas, resultando em associação positiva entre aumento do peso e trabalhar em empresa credenciada pelo PAT em 2000. Ressalta-se então, que, historicamente, as mudanças normativas do programa concentraram-se na forma de participação das empresas, em prejuízo da discussão e revisão das recomendações nutricionais. Por outro lado, o crescimento da modalidade ticket refeição reduz as chances de garantir um padrão alimentar mais adequado ao grupo de beneficiários. Nesse aspecto, a educação alimentar integrada ao programa poderia ser uma estratégia importante.

O PAT em sua origem não contemplou a educação alimentar nas suas diretrizes básicas. Essa 
lacuna só foi preenchida recentemente 30 . Uma cartilha sobre educação alimentar elaborada pelo Ministério do Trabalho e Emprego foi distribuída. Fruto das discussões do Grupo Temático de Educação Alimentar, constituído no âmbito da Comissão Tripartite, a cartilha tem como pano de fundo o quadro nutricional atual da população brasileira. A inserção da educação alimentar reflete uma tentativa de deslocar a alimentação do trabalhador do foco genuinamente energético para um enfoque de promoção à saúde e/ou prevenção de enfermidades.

Nos últimos anos mudanças vêm sendo introduzidas no programa. A participação dos trabalhadores, que vem se dando através das entidades representativas de classe na comissão instituída em 1997, pode ser entendida como um importante avanço da luta dos mesmos ao direito de participar das deliberações sobre a imple- mentação do programa. Como visto neste estudo, o programa se mostrou pouco conhecido no grupo pesquisado, mesmo entre os que referiram trabalhar. Um maior envolvimento dos trabalhadores na gestão pode colaborar para alterar essa situação.

Faz-se necessário que a avaliação de programas se constitua em uma das atividades básicas e contínuas por parte do Governo. Isso permitiria uma reorientação e/ou reformulação de suas estratégias, item este considerado falho na formulação do programa e que pode comprometer sobremaneira o alcance de seus objetivos. Também se faz necessária maior divulgação de informações sobre o PAT junto à população alvo, de forma a conscientizar os trabalhadores sobre os seus direitos e as ações desenvolvidas pelo programa.

\section{Resumo}

O estudo avaliou o Programa de Alimentação do Trabalhador (PAT) entre 1995 e 2002, sob a ótica da estrutura-processo-resultado. A metodologia consistiu em pesquisa documental e estudo de caso em $45 \mathrm{mu}$ nicípios na Bahia, resultando em 2.389 questionários domiciliares. Em termos de estrutura analisou-se a evolução normativa do programa até 2002. Quanto ao atendimento das necessidades nutricionais dos trabalhadores, o programa passou de uma insuficiente adequação calórica nos anos 80 para uma associação positiva entre sobrepeso e trabalho em empresa com PAT. Na Bahia a cobertura foi insuficiente entre os 5.120 adultos maiores de 20 anos investigados. Houve diferença significativa no acesso a benefícios alimentares entre trabalhadores do interior $(26,1 \%) e$ da capital (6,1\%). Contudo, a focalização foi adequada: todos os beneficiados no interior e 92,4\% na capital tinham renda menor que cinco salários mínimos. Faz-se necessária uma maior divulgação do PAT junto à população alvo, de forma a conscientizar os trabalhadores sobre os seus direitos e as ações desenvolvidas pelo Programa.

Segurança Alimentar e Nutricional; Programas de Nutrição; Estudos de Avaliação

\section{Agradecimentos}

Projeto financiado pela Financiadora de Estudos e Projetos com recursos do Banco Interamericano de Desenvolvimento, processo número 64.96.054900.

\section{Colaboradores}

S. M. C. Santos e L. M. P. Santos colaboraram na análise e interpretação dos dados. M. P. N. Araújo, M. C. Martins, I. S. Veloso e M. P. Assunção participaram da equipe técnica do projeto, da elaboração dos instrumentos e da coleta de dados. M. P. N. Araújo e M. C. Martins foram responsáveis pela análise dos dados empíricos aqui apresentados. Todas as autoras são responsáveis pela autoria e revisão final deste texto. 


\section{Referências}

1. Monteiro CA. Desnutrição e o planejamento econômico social. Saúde Debate 1997; (3):58-67.

2. Gambardella AMD. O Programa de Alimentação do Trabalhador frente às recomendações nutricionais para esse segmento específico da população - área metropolitana de São Paulo, São Paulo, 1990 [Dissertação de Mestrado]. São Paulo: Faculdade de Saúde Pública, Universidade de São Paulo.

3. L'Abbate S. As Políticas de Alimentação e Nutrição no Brasil: II a partir dos anos setenta. Rev Nutr PUCCAMP 1989; 2:7-54

4. Brasil. Lei no. 6.321 de 14 de abril de 1976. Dispõe sobre a dedução do lucro tributável para fins de imposto sobre a renda das pessoas jurídicas, o dobro das despesas realizadas em Programas de Alimentação do Trabalhador. Diário Oficial da União 1976; 19 abr.

5. Peliano AMTM, Castro CM, Martine G, Garcia RC. O problema alimentar brasileiro: situação atual, perspectivas e proposta de políticas. In: Castro $\mathrm{CM}$, Coimbra M, organizadores. O problema alimentar no Brasil; São Paulo: Editora da Unicamp/ Almed Editora; 1985. p. 15-43.

6. Ministério do Trabalho. Incentivos fiscais para a alimentação do trabalhador. Brasília: Secretaria de Promoção Social; 1979. (Coleção VII Promoção Social).

7. Santos SMC, Santos LMP. Avaliação de políticas publicas de segurança alimentar e combate à fome no período de 1995-2002. 1 - Abordagem metodológica. Cad Saúde Pública 2007; 23:1029-40.

8. Ministério do Trabalho. Portaria no. 3.030, de 13 de fevereiro de 1985. In: Cardápio S/C, organizador. Cardápio responde: 100 perguntas sobre o PAT. v. 6. São Paulo: Columbus Cultural Editora; 1989. p. 114-20. (Coleção Cardápio).

9. Ministério do Trabalho. Portaria no 3.282 de 27 de setembro de 1989. In: Cardápio S/C, organizador. Cardápio Responde: 100 perguntas sobre o PAT. v. 6. São Paulo: Columbus Cultural Editora; 1989. p. 124-7. (Coleção Cardápio).

10. Ministério do Trabalho. Portaria Interministerial no. 1, de 28 de janeiro de 1997. Institui Comissão Tripartite para acompanhar a execução do Programa de Alimentação do Trabalhador - PAT e dá outras providências. http://www.mte.gov.br/ Empregador/PAT/Legislacao/Conteudo/portarial.asp (acessado em 16/Jan/2007).

11. Ministério do Trabalho. Decreto ${ }^{\circ}$. 5, de 14 de janeiro de 1991. Regulamenta a Lei ${ }^{\circ}$. 6.321, de 14 de abril de 1976, que trata do Programa de Alimentação do Trabalhador, revoga o Decreto no ${ }^{\circ}$. 78.676, de 8 de novembro de 1976, e dá outras providências. http://www.trabalho.gov.br/Empregador/ $\mathrm{PAT} /$ Legislacao/Conteudo/decreto5.asp (acessado em 16/Jan/2007).
12. Ministério do Trabalho. Portaria n ${ }^{\circ}$. 87, de 28 de janeiro de 1997. Baixa instruções sobre a execução do Programa de Alimentação do Trabalhador - PAT. http://www.mte.gov.br/Empregador/pat/ Legislacao/conteudo/portaria87.asp (acessado em 16/Jan/2007)

13. Presidência da República. Medida Provisória no 1.709, de 6 de agosto de 1998. Dispõe sobre o trabalho a tempo parcial, faculta a extensão do benefício do Programa de Alimentação do Trabalhador - PAT - ao trabalhador dispensado e altera dispositivos da Consolidação das Leis do Trabalho - CLT. http://www.pge.sp.gov.br/centrodeestudos/bole tins/boljulago/lefederal.htm\#1.709 (acessado em 16/Jan/2007).

14. Ministério do Trabalho. Portaria n ${ }^{\circ}$. 03, de 01 de março de 2002. Baixa instruções sobre a execução do Programa de Alimentação do Trabalhador - PAT. http://www.mte.gov.br/Empregador/pat/ Legislacao/conteudo/portaria03.asp (acessado em 16/Jan/2007).

15. Vasconcelos FAG. Acumulação de capital, corrupção e fome. Um estudo sobre a política social de alimentação e nutrição no decorrer da Nova República e do Brasil Novo. Saúde Debate 1993; 39: 48-52.

16. Mazzon JA. O Programa Alimentação do Trabalhador: uma avaliação histórica e impactos sócio-econômicos. São Paulo: Universidade de São Paulo; 1996.

17. Araújo MPN. Programa de Alimentação do Trabalhador: estudo da evolução normativa do programa e acesso de empresa e trabalhadores baianos [Dissertação de Mestrado]. Salvador: Escola de Nutrição, Universidade Federal da Bahia; 2002.

18. Ministério do Trabalho. Portaria Interministerial $n^{\circ} .5$, de 30 de novembro de 1999. Baixa instruções sobre a execução do Programa de Alimentação do Trabalhador (PAT) http://www.mte.gov.br/Em pregador/PAT/Legislacao/Conteudo/Portaria Interministerial_n05_de_30_de_Novembro_de_ 1999.pdf (acessado em 16/Jan/2007).

19. Moura JB. Avaliação do Programa de Alimentação do Trabalhador no Estado de Pernambuco, Brasil. Rev Saúde Pública 1986; 20:115-28.

20. Costa MCSPR. Práticas alimentares, sobrepeso e perfil lipídico dos trabalhadores de uma indústria petroquímica, Camaçari - Bahia, 2000 [Dissertação de Mestrado]. Salvador: Escola de Nutrição, Universidade Federal da Bahia.

21. Veloso IS, Santana VS. Impacto nutricional do programa de alimentação do trabalhador no Brasil. Rev Panam Salud Pública 2002; 11:24-30.

22. Gomes JR. Alimentação e trabalho. Rev Bras Saúde Ocup 1982; 40:12-15. 
23. Melhado JC, Dine JM, Rosa AAP, Santos MTRS, Vaisman M. Influência do estado nutricional na produtividade de trabalhadores da construção civil no Município do Rio de Janeiro. Rev Bras Saúde Ocup 1983; 41:43-9.

24. Instituto Brasileiro de Geografia e Estatística. Pesquisa de Orçamentos Familiares 2002-3. Disponibilidade de alimentar e estado nutricional do adulto. Rio de Janeiro: Instituto Brasileiro de Geografia e Estatística; 2004.

25. Wanjek C. Food at work. Workplace solutions for malnutrition obesity and chronic diseases. Geneva: International Labour Office; 2005.

26. Mazzon JA. Programa de alimentação do trabalhador: 25 anos de contribuições ao Desenvolvimento do Brasil. São Paulo: Faculdade de Economia, Administração e Contabilidade, Universidade de São Paulo; 2001.
27. Secretaria da Receita Federal. Demonstrativo de benefícios tributários. http://www.receita.fazenda. gov.br/Historico/Arrecadacao/BenTributarios/ default.htm (acessado em 16/Jan/2007).

28. Instituto Brasileiro de Geografia e Estatística. Pesquisa Nacional por Amostra de Domicílios - PNAD 2001. http://www.ibge.gov.br/home/esta tistica/populacao/trabalhoerendimento/pnad 2001/sintese2001.pdf (acessado em 16/Jan/2007).

29. Instituto de Pesquisa Econômica e Aplicada. Um balanço das ações de governo no combate à fome e à miséria - 1993. Brasília: Instituto Pesquisa Econômica e Aplicada; 1994.

30. Departamento de Segurança e Saúde no Trabalho, Secretaria de Inspeção do Trabalho, Ministério do Trabalho. Orientação da educação alimentar. Brasília: Ministério do Trabalho; 1999.

Recebido em 23/Mar/2006

Versão final reapresentada em 23/Jan/2007

Aprovado em 24/Jan/2007 